\title{
Improved Alkyl Glycoside Synthesis by transGlycosylation through Tailored Microenvironments of Immobilized Glucosidase
}

Hoffmann, Christian; Grey, Carl; Pinelo, Manuel; Woodley, John M.; Daugaard, Anders E.; Adlercreutz, Patrick

Published in:

ChemPlusChem

Link to article, DOI:

$10.1002 /$ cplu.201900680

Publication date:

2020

Document Version

Peer reviewed version

Link back to DTU Orbit

Citation (APA):

Hoffmann, C., Grey, C., Pinelo, M., Woodley, J. M., Daugaard, A. E., \& Adlercreutz, P. (2020). Improved Alkyl Glycoside Synthesis by transGlycosylation through Tailored Microenvironments of Immobilized Glucosidase. ChemPlusChem, 151, 640-647. https://doi.org/10.1002/cplu.201900680

\section{General rights}

Copyright and moral rights for the publications made accessible in the public portal are retained by the authors and/or other copyright owners and it is a condition of accessing publications that users recognise and abide by the legal requirements associated with these rights.

- Users may download and print one copy of any publication from the public portal for the purpose of private study or research.

- You may not further distribute the material or use it for any profit-making activity or commercial gain

- You may freely distribute the URL identifying the publication in the public portal 


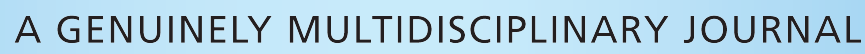 CHEMPLUSCHEM}

CENTERING ON CHEMISTRY

\section{Accepted Article}

Title: Improved Alkyl Glycoside Synthesis by trans-Glycosylation through Tailored Microenvironments of Immobilized $\beta$ Glucosidase

Authors: Christian Hoffmann, Carl Grey, Manuel Pinelo, John M Woodley, Anders Egede Daugaard, and Patrick Adlercreutz

This manuscript has been accepted after peer review and appears as an Accepted Article online prior to editing, proofing, and formal publication of the final Version of Record (VoR). This work is currently citable by using the Digital Object Identifier (DOI) given below. The VoR will be published online in Early View as soon as possible and may be different to this Accepted Article as a result of editing. Readers should obtain the VoR from the journal website shown below when it is published to ensure accuracy of information. The authors are responsible for the content of this Accepted Article.

To be cited as: ChemPlusChem 10.1002/cplu.201900680

Link to VoR: http://dx.doi.org/10.1002/cplu.201900680

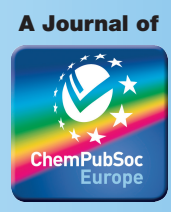


WILEY-VCH

\title{
Improved Alkyl Glycoside Synthesis by trans-Glycosylation through Tailored Microenvironments of Immobilized $\beta$ - Glucosidase
}

\author{
Christian Hoffmann ${ }^{[a]}$, Carl Grey ${ }^{[b]}$, Manuel Pinelo ${ }^{[a]}$, John M. Woodley ${ }^{[a]}$, Anders E. Daugaard ${ }^{[a] *}$, \\ Patrick Adlercreutz ${ }^{[\mathrm{b}]}$
}

\begin{abstract}
Here, we present for the first time, how the microenvironment can directly improve biocatalytic selectivity of immobilized $\beta$-glucosidase. $\beta$-Glucosidase from Thermotoga neapolitana was immobilized on a variety of functionalized offstoichiometric thiol-ene (OSTE) particles, where highest activities were observed for thiol and imidazole functional particles. Compared to the soluble enzyme, the selectivity $\left(r_{s} / r_{h}\right)$ between transglycosylation of $p$-nitrophenyl $\beta$-D-glucopyranoside (pNPG) with 1propanol over hydrolysis was increased by a factor of 2-3 using particles containing imidazole $\left(r_{s} / r_{h}\right.$ of 6.7) and carboxylic acid moieties $\left(r_{s} / r_{h}\right.$ of 9.2$)$, respectively. These results demonstrate clearly that enzyme selectivity depends directly on the local environment of the enzyme with the support.
\end{abstract}

Alkyl glycosides are amphiphilic molecules, in which a hydrophilic sugar moiety is covalently linked through a glycosidic bond to a hydrophobic alkyl chain. Due to their structure, alkyl glycosides are industrially useful as non-ionic surfactants in detergents and cosmetics. ${ }^{[1]}$ Compared to the traditional method of chemical preparation, enzymatically catalyzed synthesis of alkyl glycosides using glycoside hydrolases (EC 3.2.1) has lately received increased attention due to mild reaction conditions and high selectivity. ${ }^{[2]}$ Enzymatic glycosylation involves the reaction of an alcohol directly with a monosaccharide in reverse hydrolysis (thermodynamic control), or with a glycoside as a donor undergoing a trans-glycosylation (kinetic control). The developments within this field have been the subject of a recent mini review, which summarized different approaches in order to increase the catalytic activity, selectivity and yields. ${ }^{[3]}$ Especially the selectivity between synthesis (s) (in this case transglycosylation) and hydrolysis (h) is an important parameter that can be described as a ratio of the individual reaction rates $r_{s} / r_{h}$ or as a selectivity, $\mathrm{S}_{\mathrm{c}}$ taking the nucleophile concentrations (or activities) into account. ${ }^{[4]}$ For the synthesis of alkyl glycosides, water-miscible $^{[5]}$ as well as water-immiscible alcohols, as

[a] Dr, C, Hoffmann, Assoc. Prof. M. Pinelo, Prof. J.M. Woodley, Assoc. Prof, A.E. Daugaard

Department of Chemical and Biochemical Engineering

Technical University of Denmark

Søltofts Plads Building 229, 2800 Kgs. Lyngby, Denmark, adt@kt.dtu.dk

[b] Dr. C. Grey, Prof. P. Adlercreutz

Department of Chemistry, Division of Biotechnology

Lund University

P.O. Box 124, 22100 Lund, Swede

Supporting information for this article is given via a link at the end of the document glycoside acceptors have been studied. It has been shown that the enzyme activity and selectivity are highly dependent on the water activity ${ }^{[5,7]}$ and the alcohol concentrations and can be exploited in 2-phase systems. ${ }^{[8,9]}$ Protein engineering of $\beta$ glucosidases $^{[10]}$ as well as the choice of other glycoside hydrolases ${ }^{[11]}$ were also considered in order to improve the selectivity and activity. In addition, immobilization of $\beta$ glucosidases on commercial resins was investigated for transglycosylation reactions, resulting in improved activity and selectivity at low water activities compared to freeze-dried enzymes. ${ }^{[12]}$ Increased stability and reusability was obtained from immobilization on zinc oxide ( $\mathrm{ZnO})$ as solid support. ${ }^{[13]}$ In general, many different materials, such as chitosan, calcium alginate and polymer materials have already been applied for glycoside hydrolase immobilization. ${ }^{[14]}$ Recently, off-stoichiometric thiol-ene (OSTE) materials, being a thermosetting polymer, prepared by photochemically cross-linking of thiol and alkene (termed "ene") containing compounds, have also been used as an enzyme support. ${ }^{[15]}$ We demonstrated the development of an OSTE microtiter plate as a screening platform for a large range of surface chemistries as promising supports for the immobilization of enzymes. ${ }^{[16]}$ This type of platform allows the fast and versatile investigation of micro-environmental effects on enzyme activity, as verified by the use of horseradish peroxidase (HRP). This approach was further extended by a new method for the preparation of OSTE particles followed by versatile surface functionalization, which was successfully applied as a support for immobilization of HRP in a continuous plug-flow reactor. [17] Changes in the environmental properties at the interface between the enzyme and support surface have already been shown to be an important factor for the performance of immobilized enzymes. ${ }^{[18]}$ For immobilized $\beta$-galactosidases and lipases for instance, it has been found that a favorable environment can improve both, the stability and activity. ${ }^{[19]}$

The objective of this study was to exploit micro-environmental influences in order to promote biocatalytic activity, and more importantly selectivity, of an immobilized $\beta$-glucosidase. The goal was to increase the selectivity between trans-glycosylation (s) with 1-propanol compared to the hydrolysis (h) of p-nitrophenyl glucopyranoside (pNPG) by changing the surface chemistry of the support material and thus, the environmental properties between enzyme and support. Therefore, Thermotoga neapolitana $\beta$ glucosidase 3B (belonging to glycoside hydrolase family 3 ) was immobilized onto functional OSTE particles, which were initially prepared by suspension polymerization in glycerol using the monomers pentaerythritol tetrakis(3-mercaptopropionate) (PETMP) and 1,3,5-triallyl-1,3,5-triazine-2,4,6(1H,3H,5H)-trione (TATATO) and TPO-L as a photoinitiator. This simple method 


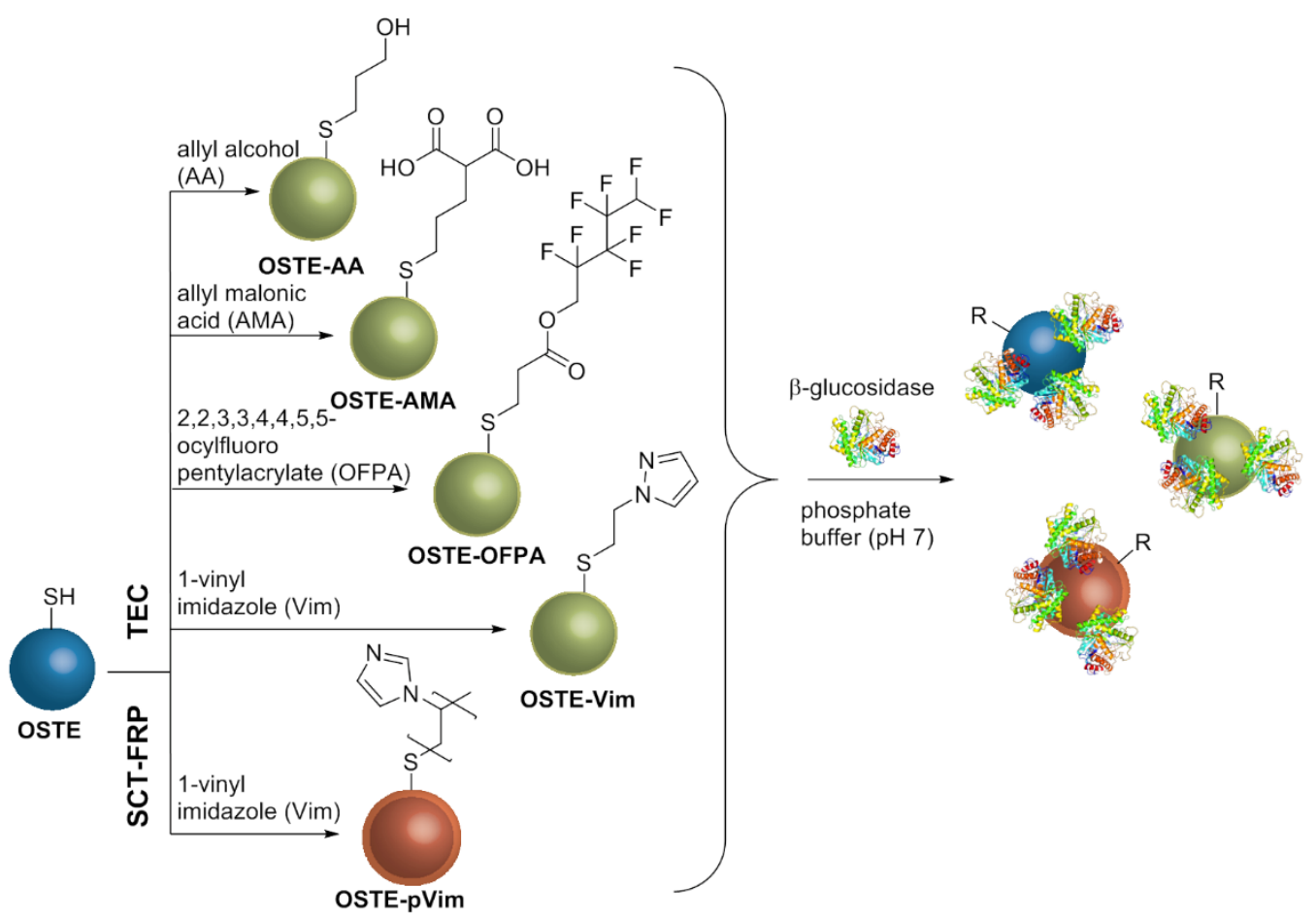

Scheme 1. Surface functionalization of OSTE particles via thiol-ene chemistry (TEC) using Vim, AA, AMA, and OFPA to introduce a functional monolayer; and via surface chain transfer free radical polymerization (SCT-FRP) using Vim to graft the surface with a dense polymer layer ( $p$ Vim) followed by immobilization of $\beta$ glucosidase on pristine and functional OSTE particles

allowed the formation of micrometer-sized monomer droplets in glycerol by rapid mixing, followed by photochemical cross-linking. The off-stoichiometric ratio between the monomers $(90 \%$ thiol in excess) resulted in thiol functional OSTE particles, which were subsequently subjected for further surface functionalization. Photochemical thiol-ene chemistry (TEC) and surface chain transfer free radical polymerization (SCT-FRP) were previously described to be efficient methods for the introduction of distinct functionalities as a functional monolayer or thicker polymer grafts. ${ }^{[17]}$ As illustrated in Scheme 1, TEC was applied with a variety of monomers, such as allyl alcohol (AA), allyl malonic acid (AMA), 2,2,3,3,4,4,5,5-octafluoropentyl acrylate (OFPA) and 1vinyl imidazole (Vim) in order to introduce different functional groups on the particle surface. Thus, hydroxyl, carboxylic acid, fluorine and imidazole functional particles were obtained. In contrast to this monolayer functionalization achieved by TEC, SCT-FRP was applied using Vim in order to create a thicker poly(1-vinyl imidazole) ( $p$ Vim) layer on the particle surface.

The chemical changes on the surface following TEC and SCTFRP were confirmed by FT-IR and $x$-ray photoelectron spectroscopy (XPS). ${ }^{[17]}$ The different functionalities in this study were selected in order to create various surface environments for the immobilization of $\beta$-glucosidase, and thus impact the enzyme performance in terms of activity and selectivity. Hydroxyl or carboxylic acid functional particles were intended to form hydrophilic interactions or hydrogen bonds, whereas fluorinated particles have the potential of creating hydrophobic interactions between the surface and the immobilized enzymes. Imidazole groups and their derivatives are known for their biological importance and have already demonstrated beneficial effects for immobilized horseradish peroxidase. ${ }^{[16]}$

As a model system, the $\beta$-glucosidase catalyzed competition reaction between trans-glycosylation and hydrolysis of $p$ nitrophenyl glucopyranoside (pNPG) was selected, as illustrated in Scheme 2. 1-Propanol was used as a water soluble glycosyl acceptor in order to obtain a one-phase reaction system with different volume ratios between alcohol and acetate buffer $(0.1 \mathrm{M}$,

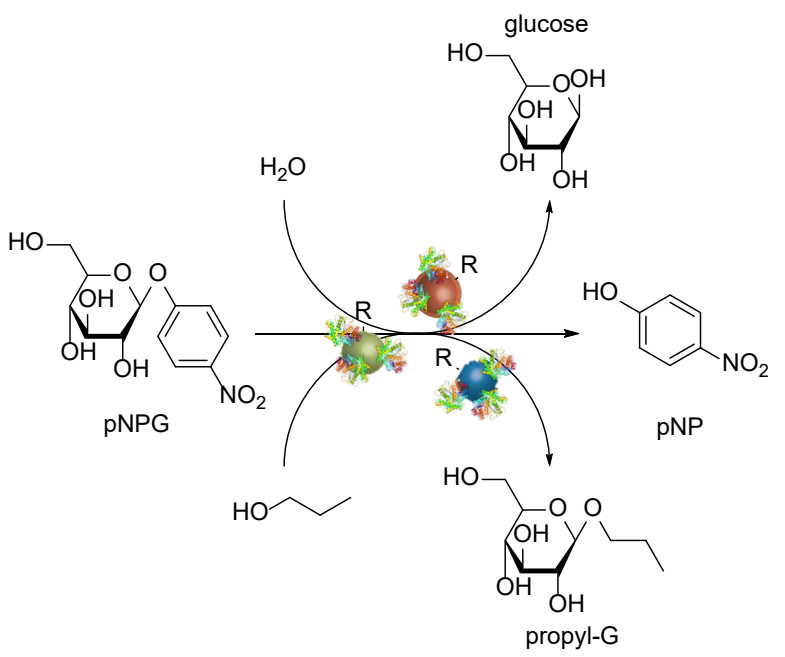

Scheme 2. Enzymatic conversion of $p$-nitrophenyl $\beta$-D-glucopyranoside (pNPG) to propyl-glucoside (propyl-G), p-nitrophenol (pNP) and glucose catalyzed by $\beta$-glucosidase immobilized on pristine and functional OSTE particles. 


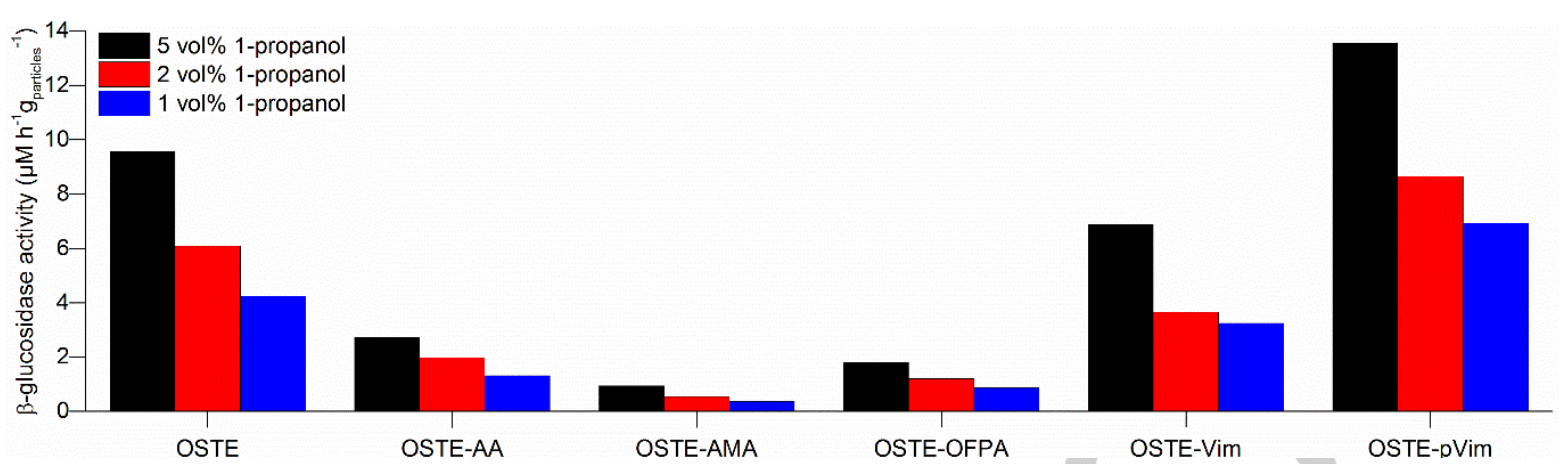

Figure 1. S Activity (combined initial reaction rates of trans-glycosylation and hydrolysis) of $\beta$-glucosidase immobilized on pristine (OSTE) and functional OSTE particles OSTE-AA, OSTE-AMA, OSTE-OFPA, OSTE-Vim and OSTE-pVim in solutions with different 1-propanol contents, such as 5, 2 and 1 vol\%.

$\mathrm{pH}$ 5.0). $\beta$-Glucosidase from Thermotoga neapolitana, which already demonstrated its potential as a catalyst for the transglycosylation of pNPG with 1-hexanol in a 2-phase system $\left(\mathrm{r}_{\mathrm{s}} / \mathrm{r}_{\mathrm{h}}=\right.$ $4.0),{ }^{[8]}$ was immobilized on pristine and functional OSTE particles (see Scheme 1). Since all surfaces have different surface chemistry, it is not possible to ensure the exact same loading of enzyme in all systems. With a fixed immobilization time of $17 \mathrm{~h}$, the amount of immobilized enzyme on each type of particle is considered only a result of surface chemistry, since all other particle properties are constant. It will therefore reflect the ability of the particles to act as immobilization systems in terms of both loading (activity) and selectivity.

Initial experiments with free $\beta$-glucosidase, in which the 1propanol content was varied from 75 to 5 vol\%, demonstrated high preference of $\beta$-glucosidase for trans-glycosylation over hydrolysis at high water contents (see Figure S1). Under these conditions, the ratio between trans-glycosylation and hydrolysis $r_{s} / r_{h}$ ranged between 28.3 and 2.6 (see Table S1).

However, it is particularly interesting to improve the selectivity even further at lower alcohol contents. In order to study the effects of the micro-environment on the enzyme selectivity with high precision, a regime with significant reaction rates for both transglycosylation and hydrolysis was chosen, which was achieved using 1-propanol contents of 5, 2, and $1 \mathrm{vol} \%$ and $95,98,99 \mathrm{vol} \%$ acetate buffer, respectively. In these experiments, the pristine and functional OSTE particles with immobilized $\beta$-glucosidase $(\approx 0.6 \mathrm{~g}$ particles) were submerged in acetate buffer/1-propanol solutions containing PNPG $(28 \mathrm{mM})$ as the substrate. The resulting enzyme activity, as combined initial reaction rate of trans-glycosylation and hydrolysis was evaluated according to the particle functionality as well as the amount of 1-propanol, which is presented in Figure 1.

From these results, a general increase in overall enzyme activity with increasing alcohol content was observed, indicating that the enzyme has a high preference for 1-propanol as acceptor substrate. Furthermore, the activity varied substantially between the individual functional particles due to micro-environmental differences around the enzyme. Depending on the amount of 1propanol, the reference OSTE particles containing $\beta$-glucosidase showed a high activity of 4.2 to $9.7 \mu \mathrm{M} \mathrm{h}^{-1} \mathrm{~g}_{\text {particles }}{ }^{-1}$, whereas a significantly lower activity was observed for hydroxyl (OSTE-AA), carboxylic acid (OSTE-AMA) and fluorine (OSTE-OFPA) functional particles. Immobilization of $\beta$-glucosidase on imidazole functional particles (OSTE-Vim) resulted in activities of 3.2 to
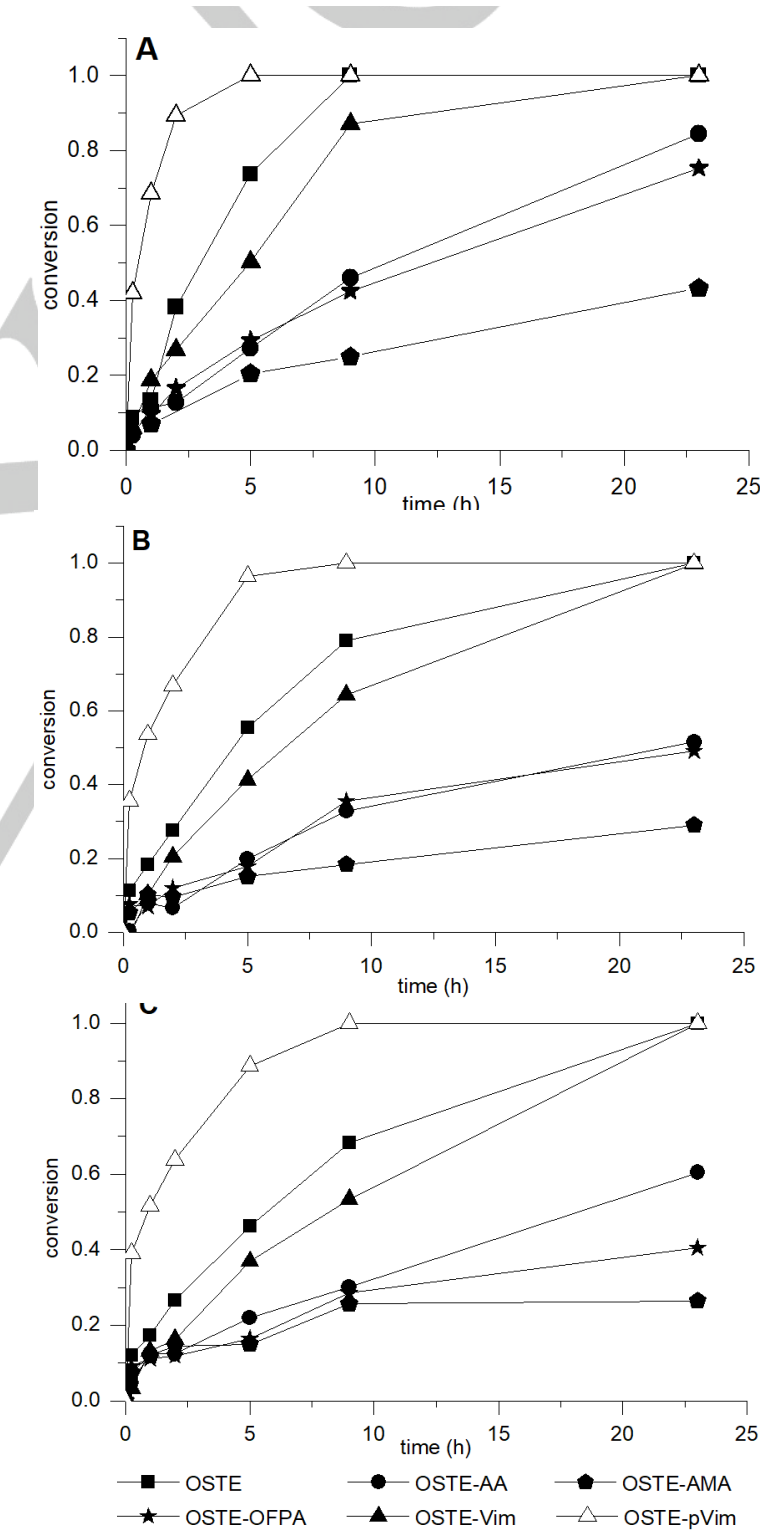

Figure 2. Time course of fractional pNPG conversion catalyzed by $\beta$ glucosidase immobilized on pristine (OSTE) and functionalized OSTE particles OSTE-AA, OSTE-AMA, OSTE-OFPA, OSTE-Vim and OSTE-pVim in reaction solution, containing (A) 5 vol\%, (B) 2 vol\% and (C) 1 vol\% 1-propanol. 
$6.9 \mu \mathrm{M} \mathrm{h}^{-1}$ gparticles $^{-1}$, which was even further increased by immobilization on the polymer grafted particles (OSTE-pVim) (6.9 - $\left.13.6 \mu \mathrm{M} \mathrm{h}^{-1} \mathrm{~g}_{\text {particles }}{ }^{-1}\right)$, corresponding to a factor of 1.4 compared to the pristine particles. Reactions ran in total for 23 hours and the conversion was monitored in time course plots as shown in Figure 2A-C. The reaction reached $100 \%$ conversion for OSTEpVim particles within 9 hours and for OSTE-Vim as well as pristine OSTE particles within 23 hours at any alcohol concentration. Whereas, for OSTE-AA (84-52\%), OSTE-AMA (43-26\%) and OSTE-OFPA (75-40\%) conversions below $100 \%$ were observed.

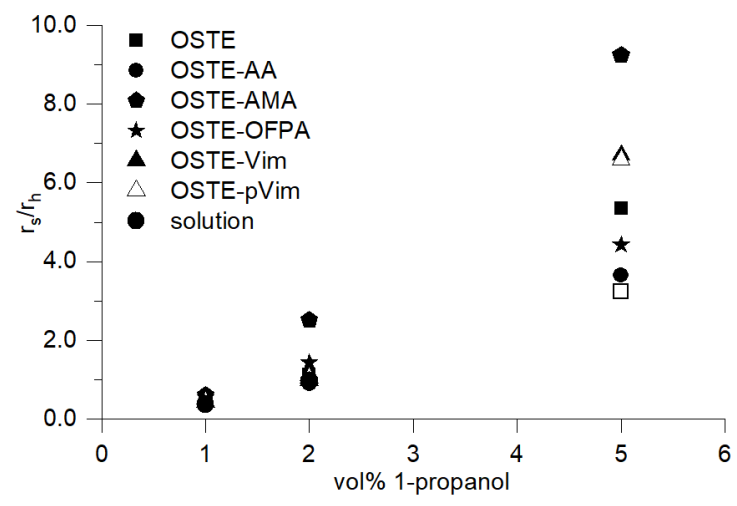

Figure 3. Selectivity (rs/rh) between trans-glycosylation (s) and hydrolysis (h) of pNPG catalyzed by $\beta$-glucosidase immobilized on pristine (OSTE) and functionalized OSTE particles OSTE-AA, OSTE-AMA, OSTE-OFPA, OSTEVim and OSTE-pVim at different 1-propanol contents.

The previously obtained activities (combined initial reaction rates) were split into the individual rates for trans- glycosylation and hydrolysis (see Table S2) in order to calculate the reactivity ratios $r_{s} / r_{h}$ for the individual particles. The ratios $r_{s} / r_{h}$ as a measure for the selectivity is presented in Figure 3 for the three different 1 propanol contents and the different particles. The selectivity $\left(r_{s} / r_{h}\right)$ improved with increasing alcohol concentration. Furthermore, the results demonstrated that the immobilization has a significant impact on selectivity, especially at higher alcohol contents. Using 1 vol\% 1-propanol, $r_{s} / r_{\text {h }}$ ratios below 1 ( 0.35 to 0.60$)$ were obtained, implying substantial preference for the hydrolysis for all types of particles as well as in solution. An increase of 1-propanol content to 2 vol\% resulted in similar trans-glycosylation and hydrolysis rates and therefore $r_{s} / r_{h}$ values of about 1 were obtained for immobilized and free enzyme. An exception being OSTE-AMA particles consisting of carboxylic acid surface moieties, which generated a preference for trans-glycosylation $\left(r_{s} / r_{h}=2.3\right)$ already at this low alcohol content. This tendency was even more pronounced at higher alcohol concentration (5 vol\%) with a $r_{s} / r_{h}$ of 9.2. The high preference for trans-glycosylation of OSTE-AMA was also seen for Vim and pVim functional (6.6/6.7), pristine OSTE (5.4), OSTE-OFPA (4.4) and OSTE-AA (3.7) particles. At this 1-propanol content, immobilization of $\beta$ glucosidase improved in each case the formation of propyl-G compared to the reaction in solution (with $r_{s} / r_{h}$ of 3.2). Particles employed in this study are only differentiated by their surface chemistry, and it is therefore possible to directly compare this influence on selectivity. It is clear that the differences in selectivity can be ascribed to the variations in surface chemistry and consequently in the generation of different enzyme-surface environments. Paricularly, the comparison of OSTE-Vim and OSTE-pVim particles, having the same functional surface (imidazole) in different concentrations (monolayer and polymer coating, respectively), illustrates how the activity can be affected by the thickness of the layer, whereas selectivity is dependent only on surface chemistry and independent of thickness. It is expected that similar correlations can be observed for other enzymes, resulting in a need to match a given immobilization system/surface to specific enzymes for optimal activity and selectivity. Future studies will be required to investigate, if specific classes of enzymes can be grouped into categories, having particularly beneficial interactions with specific surface chemistries.

In this study, we present how different surface chemistries can be exploited to improve the selectivity of trans-glycosylation over hydrolysis of $\beta$-glucosidases by changing the micro-environment through immobilization on OSTE particles with specific surface chemistries. OSTE particles were prepared by suspension polymerization in glycerol, followed by surface functionalization via TEC and SCT-FRP. Thereby particles with varied surface chemistries were prepared (on the same platform), such as hydroxyl (AA), carboxylic acid (AMA), fluorine-containing (OFPA) and imidazole (Vim and pVim) groups. $\beta$ - glucosidase from Thermotoga neapolitana, immobilized on the particles via physical adsorption, exhibited significant activity for the reaction of pNPG, depending on the surface functionality. Especially, pristine OSTE (containing surface thiols) as well as imidazole (OSTE-Vim and OSTE-pVim) functional particles demonstrated high activities between 6.9 and $13.6 \mu \mathrm{M} \mathrm{h}^{-1} \mathrm{~g}_{\text {particles }}{ }^{-1}$. Furthermore, in each case an increase in overall activity was observed with increased 1-propanol contents from 1 to 5 vol\%. Similarly, the trans-glycosylation over hydrolysis ratio increased with increasing alcohol concentration. Compared to free $\beta$-glucosidase, transglycosylation could be promoted by immobilization of the enzyme on OSTE particles. Especially at $5 \mathrm{vol} \%$ alcohol, the selectivity $r_{s} / r_{h}$ increased almost 3 fold from 3.2 up to 9.2 for carboxylic acid functional particles (OSTE-AMA), which was attributed to the specific surface chemistry. These results demonstrate clearly that variations in surface chemistry and thus, changes in surface environment, have a significant impact on the selectivity of immobilized enzymes and therefore can be used to tailor biocatalytic reactions, as demonstrated here with $\beta$-glucosidase.

\section{Experimental Section}

Materials. Pentaerythritol tetrakis(3-mercaptopropionate) (PETMP $>95 \%$ ), 1,3,5-Triallyl-1,3,5-triazine-2,4,6(1H,3H,5H)-trione (TATATO, $98 \%$ ), allyl alcohol (AA, 99\%), allyl malonic acid (AMA, $\geq 98 \%$ ), 1-vinyl imidazole (Vim, $\geq 99 \%$ ), 2,2,3,3,4,4,5,5-octafluoropentyl acrylate (OFPA, 97\%), 2,2-dimethoxy-2-phenylacetophenone (DMPA, 99\%), p-nitropheny $\beta$-D-glucopyranoside ( $p N P G, \geq 98 \%$ ), p-nitrophenol ( $p N P, \geq 98 \%$ ), n-Amyl $\beta$-D-glucopyranoside (AG, 98\%), D-(+)-glucose ( $\geq 99 \%$ ) were obtained from Sigma-Aldrich. Ethyl-2, 4, 6-tri- methylbenzoylphenyl phosphinate (Lucirin TPO-L) was obtained from BASF. Ethanol absolute $(99.97 \%$ ) was purchased from WWR. Glycerol was kindly provided by Emmelev, Otterup A/S Denmark and was used as received. Thermotoga neapolitana $\beta$ glucosidase 3B (EC 3.2.1.21) was obtained from Escherichia coli batch cultivations. It was purified using a two-step protocol, including heat treatment of the cell extract $(70 \circ \mathrm{C}, 30 \mathrm{~min})$, which was followed by 
immobilized metal ion affinity chromatography using the supernatant from the heat treatment step as described by Pozzo et al. The enzyme was stored at $4{ }^{\circ} \mathrm{C}$ until use. ${ }^{[20]}$

Methods. $\beta$-glucosidase reactions were followed using HPLC (LaChrom; pump L-7100, interface L-7000, autosampler L- 7250 with a $20 \mathrm{ml}$ injection loop, UV-detector L7400, Hitachi Ltd. Tokyo, Japan) equipped with an evaporative light scattering detector (Alltech $500 \mathrm{ELSD}$, Alltech Associates Inc., Deer-field, USA) with evaporator temperature $78^{\circ} \mathrm{C}$, a nebulizer gas flow of 2.0 standard liters per minute and a Kromasil 100-5-NH2 column (4.6 $\mu \mathrm{m} \times 250 \mathrm{~mm}$, Kromasil). Isokratic conditions with $85 \%$ acetonitrile and $15 \% \mathrm{MQ}$ water under a constant flow rate of $1.0 \mathrm{ml} \mathrm{min}^{-1}$ were used. pNP has a retention time of 4.1 and was monitored at $405 \mathrm{~nm}$ using the UV detector. pNPG elutes after $4.9 \mathrm{~min}$ and was followed at $405 \mathrm{~nm}$ as well as with ELSD. PG eluted after $6.2 \mathrm{~min}$ and glucose after $13.8 \mathrm{~min}$, both were detected by ELSD. Concentrations were determined by use of 8 point external standard curves. For PG no standard was available, therefore the calibration was prepared using $n$-amyl $\beta$-D-glucopyranoside. Combined initial reaction rates taking both, trans-glycosylation and hydrolysis into consideration, were estimated from the initial changes in molar concentration of pNPG over time. Similarly, the individual initial reaction rates for trans-glycosilation and hydrolysis were estimated using the initial changes molar concentrations over time of propyl-G and glucose, respectively.

Preparation off-stoichiometric thiol-ene (OSTE) particles. TPO-L (3.0 $\mathrm{mg}, 0.1 \mathrm{wt} \%)$, PETMP (2.217 g, $0.0012 \mathrm{~mol})$, TATATO (0.794 g, 0.0016 $\mathrm{mol})$, and glycerol $(30 \mathrm{~mL})$ were added into a mixing cup under exclusion of light. Then, the mixture was mixed in a Speedmixer at $1000 \mathrm{rpm}$ (SpeedMixerTM DAC 150.1 FVZ) for 1.5 minutes before the formed emulsion was exposed to UV light ( $\left.\lambda=365 \mathrm{~nm}, 1.4 \mathrm{~mW} \mathrm{~cm}^{-2}\right)$ for 10 minutes Subsequently, ethanol was added to the formed particles in glycerol, which was homogenized by brief manual stirring and the resulting particles were filtered and thoroughly rinsed with ethanol.

Surface functionalization of OSTE particles via thiol-ene chemistry (TEC). In a general procedure, the full batch of previously prepared OSTE particles was directly submerged in a solution containing 1-vinyl imidazole $(0.824 \mathrm{~mL}, 0.009 \mathrm{~mol})$, TPO-L $(28.6 \mathrm{mg})$ and $20 \mathrm{~mL}$ ethanol. After magnetically stirring for $5 \mathrm{~min}$ under light exclusion, the stirring mixture was exposed to UV-light $\left(\lambda=365 \mathrm{~nm}, 1.4 \mathrm{~mW} \mathrm{~cm}^{-2}\right)$ for 5 minutes. Thereafter, the particles were filtered and thoroughly rinsed with ethanol before drying in vacuo overnight, which led to a white material $(2.1459 \mathrm{~g}$, yield $71 \%$ ).

Surface functionalization via allyl alcohol (AA) by TEC. OSTE-AA was prepared in accordance to the general procedure, using $20 \mathrm{~mL}$ of an ethanolic solution of allyl alcohol (AA, $408 \mu \mathrm{L}, 6.0 \mathrm{mmol}$ ) and TPO-L (28.6 $\mathrm{mg}$ ) as reagent.

Surface functionalization via allyl malonic acid (AMA) by TEC. OSTEAMA was prepared in accordance to the general procedure, using $20 \mathrm{~mL}$ of an ethanolic solution of allyl malonic acid (AMA, $0.864 \mathrm{~g}, 6.0 \mathrm{mmol})$ and TPO-L (28.6 $\mathrm{mg})$ as reagent.

Surface functionalization via $2,2,3,3,4,4,5,5$ octafluoropentyl acrylate (OFPA) by TEC. OSTE-OFPA was prepared in accordance to the general procedure, using $20 \mathrm{~mL}$ of an ethanolic solution of 2,2,3,3,4,4,5,5 octafluoropentyl acrylate (OFPA, $1.36 \mathrm{~mL}, 6.0 \mathrm{mmol})$ and TPO-L $(28.4 \mathrm{mg}$ ) as reagent.

Surface functionalization of OSTE particles via surface chain transfer free radical polymerization (SCT FRP) with 1-vinyl imidazole (OSTEpVim). In a general procedure, the full batch of previously prepared OSTE particles was submerged in a solution containing 1-vinyl imidazole (Vim,
$10.4 \mathrm{~mL}, 0.115 \mathrm{~mol}$ ), 2,2-dimethoxy-2-phenylacetophenone (DMPA, 142.8 $\mathrm{mg}, 0.50 \mathrm{~mol} \%)$ and ethanol $(20 \mathrm{~mL})$, which was screened from ambient light. Under magnetic stirring, this mixture was subsequently irradiated with UV light ( $\left.\lambda=365 \mathrm{~nm}, 0.4 \mathrm{~mW} \mathrm{~cm}^{-2}\right)$ for $30 \mathrm{~min}$. Thereafter, the particles were filtered and thoroughly rinsed with ethanol before drying in vacuo overnight, which led to a light yellow material.

Immobilization of $\beta$-glucosidase. $1.5 \mathrm{~g}$ of the previously functionalized particles was resuspended in ethanol, which was subsequently 4 times solvent exchanged by phosphate buffer $(0.1 \mathrm{M}, \mathrm{pH} 7.2)$. The final amount of buffer was $7.5 \mathrm{~mL}$ and $\beta$-glucosidase $\left(7.5 \mathrm{mg}, 1.0 \mathrm{mg} \mathrm{mL}^{-1}\right)$ was added to this mixture. The suspension was incubated under shaking at $4{ }^{\circ} \mathrm{C}$. After $17 \mathrm{~h}$ the particles were filtered under suction and thoroughly washed with phosphate buffer $(0.1 \mathrm{M}, \mathrm{pH} 7.2)$.

Selectivity study of immobilized $\beta$-glucosidase. The particles used for immobilization of $\beta$-glucosidase were directly after filtration divided into three equal sized portions. To portion $1(0.6724 \mathrm{~g}), 4 \mathrm{~mL}$ of a mixture of acetate buffer $(0.1 \mathrm{M}, \mathrm{pH} 5.0)$ and 1-propanol in a volume ratio of $95: 5$ containing PNPG $(28 \mathrm{mM})$ was added. Similarly, to portion $2(0.6570 \mathrm{~g})$ and portion $3(0.6872 \mathrm{~g}), 4 \mathrm{~mL}$ of an acetate buffer/1-propanol mixture in a volume ratio of $98: 2$, and $99: 1$ vol\% containing each pNPG $(28 \mathrm{mM})$ was added. These suspensions were vortex mixed for $10 \mathrm{~s}$ and subsequently incubated under shaking $(750 \mathrm{rpm})$ at $37^{\circ} \mathrm{C}$. Samples of the supernatant $(100 \mu \mathrm{L})$ were withdrawn after $0,0.25,0.5,1,2,5,9$ and 23 h. To each aliquot, $100 \mu \mathrm{L}$ of a $\mathrm{NaOH}$ solution $(2 \mathrm{mM})$ and $500 \mu \mathrm{L}$ of acetonitrile were added, and the final samples were analyzed by HPLC.

Selectivity study of free $\beta$-glucosidase. To $2.0 \mathrm{~mL}$ of a $95: 5$ vol\% acetate buffer $(0.1 \mathrm{M}, \mathrm{pH} 5.0) / 1$-propanol solution containing pNPG (28 $\mathrm{mM}$ ), $5 \mu \mathrm{L}$ of dissolved $\beta$-glucosidase (in phosphate buffer, $0.1 \mathrm{M}, \mathrm{pH} 7.3$, $3.95 \mathrm{mg} \mathrm{mL}^{-1}$ ) was added resulting in a final enzyme concentration of 9.85 $\mu \mathrm{gL}^{-1}$. In the same way, a $98: 2$ vol\% acetate buffer $(0.1 \mathrm{M}, \mathrm{pH} 5.0) / 1$. propanol solution containing pNPG $(28 \mathrm{mM})$ and a $99: 1 \mathrm{vol} \%$ acetate buffer $(0.1 \mathrm{M}, \mathrm{pH}$ 5.0)/1-propanol solution containing pNPG ( $28 \mathrm{mM})$ were used. These reaction mixtures were incubated at $37^{\circ} \mathrm{C}$ under shaking $(750$ $\mathrm{rpm})$ and samples $(100 \mu \mathrm{L})$ were withdrawn after $0,0.25,0.5,1,2,5,9$ and $23 \mathrm{~h}$. To each aliquot, $100 \mu \mathrm{L}$ of a $\mathrm{NaOH}$ solution $(2 \mathrm{mM})$ and $500 \mu \mathrm{L}$ of acetonitrile were added, and the final samples were analyzed by HPLC.

\section{Acknowledgements}

Financial support from the Aage and Johanne Louis-Hansens Endowment is gratefully acknowledged.

Keywords: Alkyl glycoside - Enzyme immobilization $\cdot$ Hydrolase - Surface functionalization - Trans-glycosylation

[1] a) H. Andree, J. F. Hessel, P. Krings, G. Meine, B. Middelhauve, K. Schmid, in Alkyl Polyglycosides Technol. Prop. Appl. (Eds.: K. Hill, W. von Rybinski, G. Stoll), John Wiley \& Sons, Inc., 2008, pp. 99-130. b) H. Tesmann, J. Kahre, H. Hensen, B. A. Salka, in Alkyl Polyglycosides Technol. Prop. Appl. (Eds.: K. Hill, W. von Rybinski, G. Stoll), John Wiley \& Sons, Inc., 2008, pp. 71-98.

[2] a) B. M. De Roode, M. C. R. Franssen, A. Van Der Padt, R. M. Boom, Biotechnol. Prog. 2003, 19, 1391-1402. b) M. Rather, S. Mishra, Sustain. Chem. Process. 2013, $1,7$. 
[3] P. Adlercreutz, Appl. Microbiol. Biotechnol. 2017, 101, 513519.

[4] Van Rantwijk, M. Woudenberg-Van Oosterom, R. A. Sheldon, J. Mol. Catal. - B Enzym. 1999, 6, 511-532.

[5] T. Hansson, M. Andersson, E. Wehtje, P. Adlercreutz, Enzyme Microb. Technol. 2001, 29, 527-534.

[6] N. J. Parry, D. E. Beever, E. Owen, I. Vandenberghe, J. Van Beeumen, Mm. K. Bhat, Biochem. J. 2001, 353, 117-127.

[7] a) G. Ljunger, P. Adlercreutz, B. Mattiasson, Enzyme Microb. Technol. 1994, 16, 751-755. b) T. Hansson, P. Adlercreutz, Biotechnol. Bioeng. 2001, 75, 656-665. c) I. Mladenoska, Food Technol. Biotechnol. 2016, 54, 211-216.

[8] P. Turner, D. Svensson, P. Adlercreutz, E. N. Karlsson, J. Biotechnol. 2007, 130, 67-74.

[9] D. H. Guo, Y. S. Xu, Y. J. Kang, S. Y. Han, S. P. Zheng, Enzyme Microb. Technol. 2016, 85, 90-97.

[10] P. Lundemo, P. Adlercreutz, E. N. Karlsson, Appl. Environ. Microbiol. 2013, 79, 3400-3405.

[11] a) M. R. Martearena, S. Blanco, G. Ellenrieder, Bioresour. Technol. 2003, 90, 297-303. b) J. Larsson, D. Svensson, P. Adlercreutz, J. Mol. Catal. B Enzym. 2005, 37, 84-87. c) D. Svensson, S. Ulvenlund, P. Adlercreutz, Biotechnol. Bioeng. 2009, 104, 854-861.

[12] P. Lundemo, E. N. Karlsson, P. Adlercreutz, J. Mol. Catal. B Enzym. 2014, 108, 1-6.

[13] P. Kumar, B. Ryan, G. T. M. Henehan, Protein Expr. Purif. 2017, 132, 164-170.
[14] N. G. Graebin, J. D. N. Schöffer, D. De Andrades, P. F. Hertz, M. A. Z. Ayub, R. C. Rodrigues, Molecules 2016, 21, 138.

[15] a) E. Cakmakci, O. Danis, S. Demir, Y. Mulazim, M. V. Kahraman, J. Microbiol. Biotechnol. 2013, 23, 205-210. b) J. P. Lafleur, S. Senkbeil, J. Novotny, G. Nys, N. Bøgelund, K. D. Rand, F. Foret, J. P. J. P. Kutter, Lab Chip 2015, 15, 1-2. c) E. Çakmakçi, B. Yuce-Dursun, S. Demir, React. Funct. Polym. 2017, 111, 38-43.

[16] C. Hoffmann, M. Pinelo, J. M. Woodley, A. E. Daugaard, Biotechnol. Prog. 2017, 33, 1267-1277.

[17] C. Hoffmann, V. Chiaula, L. Yu, M. Pinelo, J. M. Woodley, A. E. Daugaard, Macromol. Rapid Commun. 2018, 39, 1700394.

[18] J. C. S. Dos Santos, O. Barbosa, C. Ortiz, A. BerenguerMurcia, R. C. Rodrigues, R. Fernandez-Lafuente,

ChemCatChem 2015, 7, 2413-2432.

[19] a) C. Giacomini, G. Irazoqui, F. Batista-Viera, B. M. Brena, J. Mol. Catal. B Enzym. 2001, 11, 597-606. b) G. Irazoqui, A. Villarino, F. Batista-Viera, B. M. Brena, Biotechnol. Bioeng. 2002, 77, 430-434. c) J. Liu, S. Bai, Q. Jin, H. Zhong, C. Li, Q. Yang, Langmuir 2012, 28, 9788-9796. d) O. Barbosa, R. Torres, C. Ortiz, Á. Berenguer-Murcia, R. C. Rodrigues, R. FernandezLafuente, Biomacromolecules 2013, 14, 2433-2462. e) J. C. S. dos Santos, N. Rueda, L. R. B. Goncalves, R. FernandezLafuente, Enzyme Microb. Technol. 2015, 77, 1-7.

[20] T. Pozzo, J. L. Pasten, E. N. Karlsson, D. T. Logan, J. Mol. Biol. 2010, 397, 724-739. 
Entry for the Table of Contents (Please choose one layout)

Layout 1:

\section{COMMUNICATION}

The impact on activity and selectivity as an effect of the local microenvironment was investigated for immobilized $\beta$-glucosidase from Thermotoga neapolitana. The enzyme was immobilized on thiol-ene (OSTE) particles having hydrophilic, hydrophobic, hydrogen accepting and hydrogen donating surfaces. Compared to the soluble enzyme, the selectivity between trans-glycosylation of p-nitrophenyl $\beta$-D-glucopyranoside (pNPG) with 1-propanol over hydrolysis was significantly increased for imidazole and carboxylic acid surfaces.

Layout 2:

\section{COMMUNICATION}

Christian Hoffmann, Carl Grey, Manuel Pinelo, John M. Woodley, Anders E. Daugaard*, Patrick Adlercreutz

Page No. - Page No.

Improved alkyl glycoside synthesis by trans-glycosylation through tailored microenvironment of immobilized $\beta$ glucosidase
Author(s), Corresponding Author(s)*

Page No. - Page No.

Title

Text for Table of Contents 